Bull. Mater. Sci., Vol. 2, Number 3, August 1980, pp. 155-159. (C) Printed in India.

\title{
Electrowinning of cerium group metals from fused chloride bath
}

\author{
SOHAN SINGH and A L PAPPACHAN \\ Metallurgy Division, Bhabha Atomic Research Centre, Trombay, Bombay 400 085, \\ India
}

MS received 10 April 1980

\begin{abstract}
Cerium group metals, namely, misch metal, lanthanum and cerium have been electrowon from their vacuum-dehydrated chlorides in fused sodium chloridepotassium chloride and lithium chloride-potassium chloride solvent. Temperature, cathode current density and composition of bath were optimised for high current efficiency and metal yield. In the case of lanthanum, current efficiency of $88 \%$ was achieved. The metals were free from inclusions and voids and analysed $99 \%+$. The major non-rare earth metallic impurities were $\mathrm{Fe}, \mathrm{Mg}$ and $\mathrm{Al}$. The total gaseous impurities for lanthanum and misch metal were not more than $0.017 \%$.
\end{abstract}

Keywords. Electrowinning; fused chloride; cerium; lanthanum.

\section{Introduction}

The development of rare earth industry has special significance to India, because of the availability of the rich resources of monazite mineral which is estimated to be about 5 million tons. A phosphate of thorium and rare earths, monazite contains $60-61 \%$ rare earth oxides mainly of cerium group. As more and more applications of rare earths are discovered their demand is steadily increasing. The need of pure metals for various branches of science and technology demands new methods of production.

The multiple new applications of rare earths in the form of metals, alloys or compounds in the fields of metallurgy, electronics, chemical, magnetics, medical, nuclear, etc. promise to dwarf the classic uses for glass polishing, lighter flints and carbon arc. Some of the important applications of rare earths in the field of metallurgy are : as nodularising agent for cast iron to improve strength and ductility, deoxidising and desulphurising agent for various steels, to inhibit hydrogen embrittlement in high strength steels. In non-ferrous metallurgy its applications are : to reduce microporosity in magnesium alloys, to improve tensile strength and heat resistance of high transmission lines and as hardening agent for copper alloys.

This paper summarises some of the work being carried out to electrowin cerium group metals by fused salt electrolysis, which is an alternate route to metallothermic reduction. The metals are electrowon in the molten state by operating the bath 
well above their melting point. This technique has the advantages of (i) easy metalelectrolyte separation (ii) metal is obtained in the consolidated form and (iii) low surface area of metal and hence lower degree of contamination.

\section{Experimental}

Efforts were directed to have pure metals with high current efficiency and metal yield. A brief description of bath, feed stock preparation and electrolytic cell is summarised in this section.

\subsection{Selection of bath}

Sodium chloride-potassium chloride and lithium chloride-potassium chloride at their eutectic composition were selected as solvent electrolyte for rare earth chloride, because of the following properties : (i) thermal stability of the salts at the working temperature, (ii) suitable physico-chemical properties like low melting point, high specific conductivity and low value of viscosity and vapour pressure, (iii) high solubility of rare earth chloride in solvent salts and (iv) higher decomposition potential compared to rare earth chlorides. Though the chlorides of rare earths are highly hygroscopic, they have advantages over fluorides in having low working temperature, high solubility in water and are comparatively cheaper.

\subsection{Preparation of chloride feed stock}

Chlorides of lanthanum and cerium were prepared by refluxing their oxides of $99.9 \%$ purity with conc. hydrochloric acid. In the case of cerium, reduction of $\mathrm{Ce}^{4+}$ to $\mathrm{Ce}^{3+}$ takes place during chlorination and free chlorine is evolved. The chloride solution was concentrated under reduced pressure. The detailed procedure for obtaining anhydrous chloride has been reported (Sohan Singh and Balchandra 1973). For misch metal, mixed rare earth chlorides were dehydrated. Dehydration of rare earth chlorides in presence of ammonium chloride was not found to be suitable as traces of ammonium chloride left had deleterious effects on the metal produced. The dehydrated chloride of rare earth was mixed thoroughly with the required amount of solvent eutectic.

\subsection{Electrolytic cell}

Since these metals are highly reactive especially in molten state, it is difficult to have a choice of material of construction which is chemically inert at working temperature beside being thermal shock resistant. Graphite crucible has been used as container for fused electrolyte as well as anode and molybdenum was used as cathode. The molten metal has been collected in an oxide refractory crucible kept under the cathode. Alumina crucibles were found to be most satisfactory, though zirconia and tantalum crucibles were also used. The electrolytic cell has been designed for easy melt-electrolyte separation (figure 1). The cell with an outlet at the bottom to remove molten electrolyte was designed to handle charge of 6-7 kg. In all these experiments pre-electrolysis was carried out at low voltage using a graphite cathode to remove traces of moisture. Argon was used as protective atmosphere for all experiments. 


\section{Results and discussion}

The variation of current efficiency (CE) vs temperature has been carried out to determine the optimum temperature for electrolysis. Figure 2 shows that in the case of misch metal the current efficiency increases with increase in temperature reaching a maximum at $950^{\circ} \mathrm{C}$ and decreasing thereafter. For cerium and lanthanum the suitable temperature was found to be $900^{\circ} \mathrm{C}$ and $960^{\circ} \mathrm{C}$ respectively. At lower temperature coalscence of metal is incomplete while at higher temperature the metal solubility in its melt increases.

The effect of cathode current density (CCD) on the current efficiency has been studied in 5 to $10 \mathrm{~A} / \mathrm{cm}^{2} \mathrm{CCD}$ range and the results have been presented in figure 3. The $\mathrm{CE}$ generally increases with increase in CCD in all cases. High

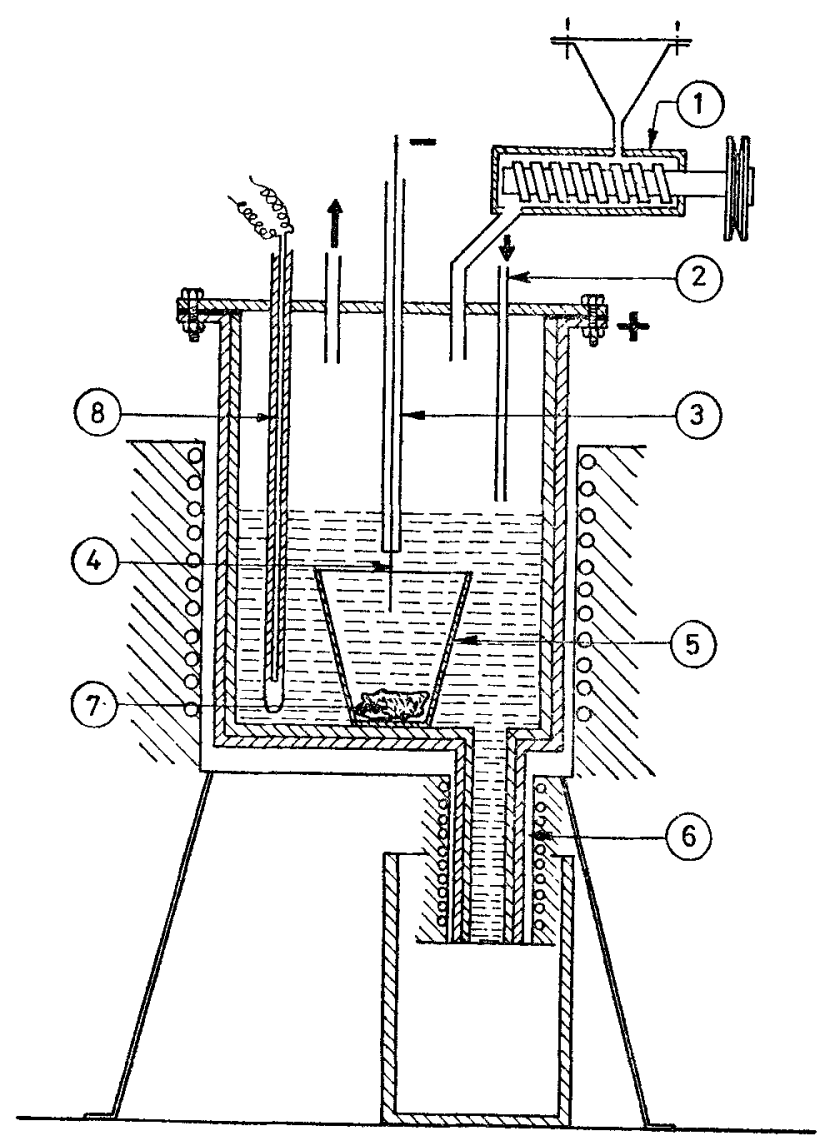

1. Screw feeder

3. Cathode sheath

2. Argon inlet

5. Alumina crucible

7. Molten metal

4. Molybdenum cathode

6. Outlet for molten salt

8. Thermocouple with sheath

Figure 1. Electrolytic cell. 
CCD of the order of 5-7 A/ $/ \mathrm{cm}^{2}$ helps in localisation of metal. In case of lanthanum and misch metal after reaching a maximum of $88 \%$ and $54 \%$ current efficiency

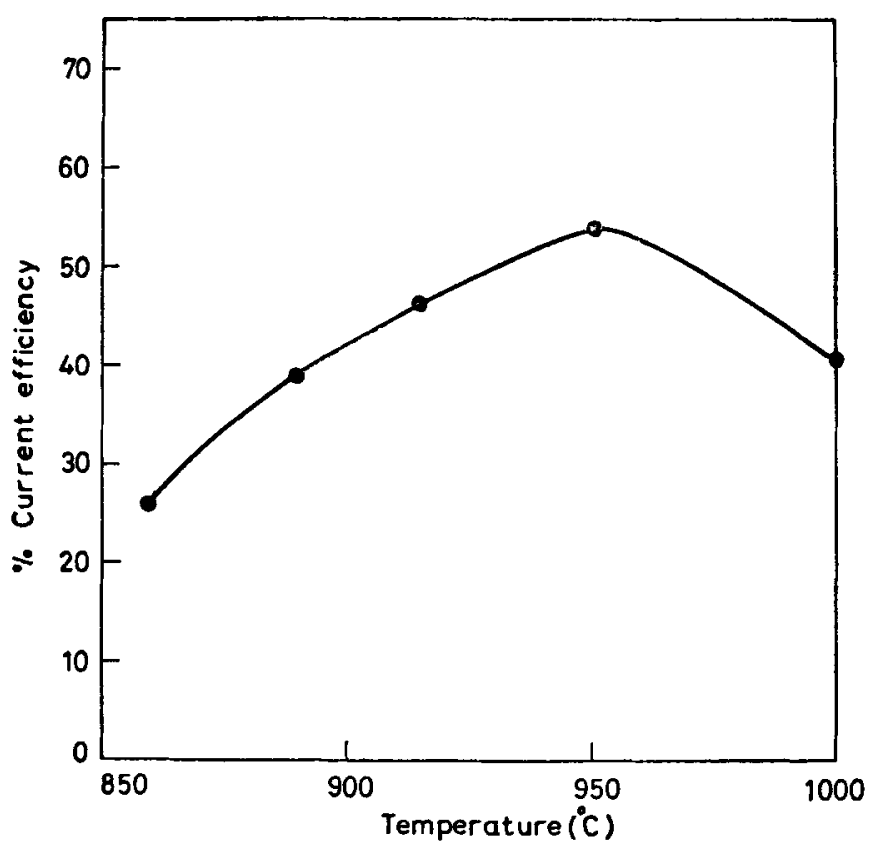

Figure 2. Temperature vs current efficiency for misch metal.

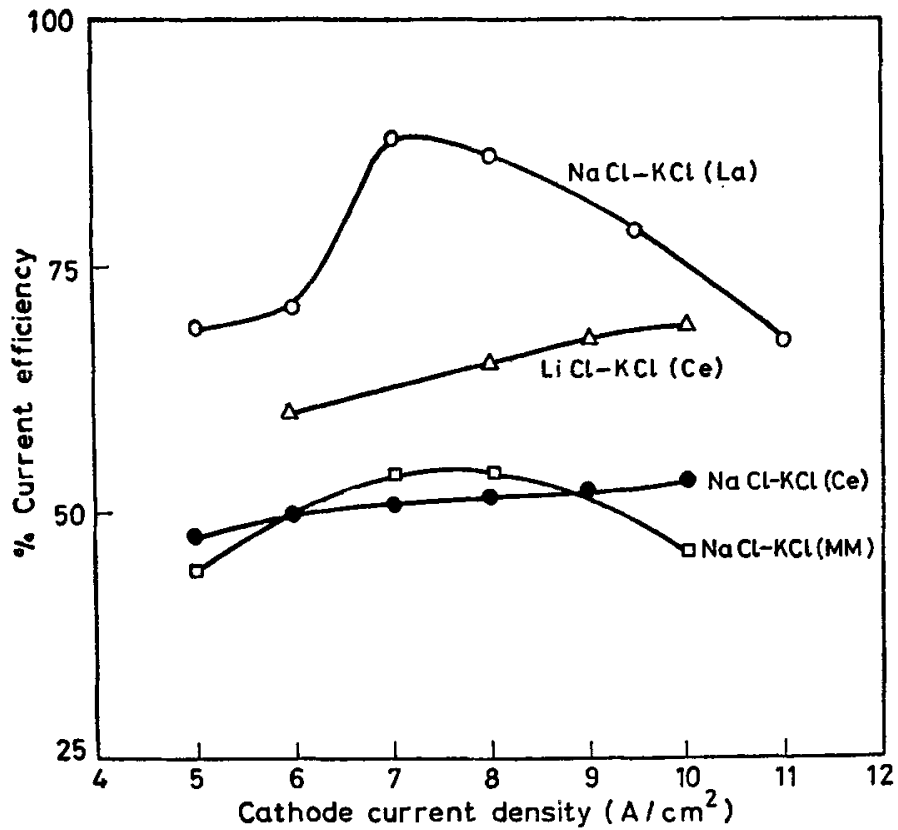

Figure 3. Cathode current density vs current efficiency. 
at 7 and $7.6 \mathrm{~A} / \mathrm{cm}^{2}$ respectively, a decrease in $\mathrm{CE}$ is observed with further increase of CCD. The possible reason for decrease of $\mathrm{CE}$ at very high CCD is co-reduction of solvent ions at cathode. No such maxima were found in cerium. Perhaps still higher CCD is needed for co-reduction of solvent because part of the energy is lost due to cyclic oxidation-reduction of cerium ion.

It was observed that metal yield improved by continuously feeding the rare earth chloride in melt during electrolysis to maintain its concentration between 30 and $50 \mathrm{w} \%$. The metal yield also improved by passing excess ampere hour (AH) than required theoretically.

\section{Analysis}

Metal ingots fully coalesced, free from inclusions and voids were obtained, which always analysed $99 \%^{+}$with $\mathrm{Fe}, \mathrm{Mg}$ and $\mathrm{Al}$ as major non-rare earth metallic impurities. The total gaseous impurities of nitrogen, hydrogen and oxygen were around 0.016 to $0.017 \mathrm{w} \%$. Only in cerium the oxygen impurity was $0.5 \mathrm{w} \%$.

\section{Conclusion}

Misch metal, cerium and lanthanum metals have been prepared in $1 \mathrm{~kg}$ per batch. Parameters were standardised to get maximum current efficiency and metal yield. Metals are better than $99 \%$ purity. Only in cerium the major gaseous impurity is oxygen.

\section{Acknowledgements}

The authors are thankful to Shri C V Sundaram, Head, Metallurgy Division for his keen interest during the course of this investigation and to Dr H S Gadiyar for his valuable discussion during the preparation of the paper. Thanks are due to Shri P K Wahi of Spectroscopy Division, Bhabha Atomic Research Centre for analysis of gases in metals.

\section{Reference}

Sohan Singh and Balachandra J 1973 J. Electrochem. Soc. (India) 22222 